\title{
Comentario acerca del trabajo Rocha MJ. Brucelosis espinal
}

\author{
Acta Médica Grupo Ángeles 2016 oct.-dic.;14(4):211-219
}

\section{Dr. Raúl Ariza Andraca Editor de Acta Médica Grupo Ángeles}

Señor editor:

En un reciente artículo sobre brucelosis, ${ }^{1}$ en el apartado "Discusión" del mismo, dice: "la prueba de aglutinación para Brucella (títulos mayores de 1:160) es muy confiable, con $97 \%$ de positividad en personas infectadas a las tres semanas de la exposición" y "la respuesta al tratamiento suele ser monitorizada con pruebas repetidas de aglutinación y los antibióticos deben mantenerse hasta que los títulos desciendan a 1:160 o menos".

Lo anterior da pie para hacer algunas breves reflexiones sobre las llamadas "reacciones febriles" como método paraclínico de diagnóstico.

La serología como método paraclínico de diagnóstico en los casos de fiebre tifoidea y brucelosis alcanzó gran popularidad en décadas pasadas (1940-1980).2,3 Posteriormente, ha disminuido el empleo de este método laboratorial; ${ }^{3}$ incluso, se ha llegado a considerar que carece de utilidad ${ }^{4}$ y cuestionar la persistencia de su uso entre la comunidad médica. ${ }^{5}$

Sin duda, con valor absoluto, ${ }^{3}$ el diagnóstico definitivo de tifoidea, paratifoidea y brucelosis es el aislamiento ${ }^{4}$ $(\text { cultivo })^{3}$ del germen en sangre, médula ósea, heces fecales, orina o líquido cefalorraquídeo. ${ }^{4}$ Los cultivos deberán hacerse antes de usar antibióticos; actualmente hay más posibilidades de éxito que hace apenas unos años, ya que se utilizan hemolizantes que no afectan la viabilidad de las bacterias y permiten el aislamiento en menos de una semana. ${ }^{4,6}$

Sin embargo, sin llegar a los extremos señalados, ${ }^{4,5}$ en nuestros países, de escasos recursos económicos, se pueden

Correspondencia:

Dr. Guillermo Murillo-Godínez

Correo electrónico: tlmx2167747@prodigy.net.mx

Aceptado: 09-03-2017.

Este artículo puede ser consultado en versión completa en http:// www.medigraphic.com/actamedica seguir usando las reacciones serológicas tradicionales, ${ }^{3}$ siempre y cuando se tomen en cuenta determinados lineamientos:

Para el caso de la brucelosis, al igual que los antígenos "O" y " $\mathrm{H}$ " de Salmonella, algunos autores han considerado como normales ${ }^{7}$ niveles de hasta 1:80. En sujetos con infección activa por Brucella, los anticuerpos suelen aumentar hasta después de dos a tres semanas de instalada la infección y alcanzan su nivel máximo de expresión a las cuatro u ocho semanas. La ausencia de estos anticuerpos no excluye la existencia de la enfermedad. ${ }^{6}$

En el caso de la fiebre tifoidea, es recomendable emplear dos pruebas, una muy sensible (Welch-Stuart) y una muy específica (Widal). ${ }^{3}$

Para las reacciones febriles en general, se pueden hacer los siguientes comentarios, ${ }^{6}$ algunos de ellos propuestos, incluso, ${ }^{8}$ por los mismos actuales detractores: ${ }^{4,5}$

No solicitar el estudio antes de una semana de iniciada la fiebre.

El título de aglutinación de una sola determinación no tiene valor diagnóstico. Es recomendable indicar al laboratorio, conservar congelada la primera muestra y, si fuera necesario, procesarla nuevamente con fines comparativos junto con una segunda muestra obtenida una semana después.

Solo el incremento del título de aglutinación de cuatro o más veces entre muestras obtenidas en fechas diferentes puede considerarse evidencia inequívoca de infección reciente.

En condiciones ideales, deben investigarse rutinariamente anticuerpos IgG e IgM. Si no se encuentran estos anticuerpos, el paciente no está infectado o la muestra fue obtenida antes de iniciada la respuesta inmune. Si solo se encuentran anticuerpos IgM, el individuo está expuesto a la infección. Esto ocurre también como resultado de vacunación para la tifoidea. Si solo se encuentran anticuerpos IgG y no IgM, el sujeto tiene inmunidad para el agente etiológico, pero no necesariamente sufre la infección.

Con frecuencia dificultan la interpretación de los resultados las reacciones cruzadas que se observan en algunas personas, además de los portadores de anticuerpos adquiridos por exposiciones previas o que fueron vacunados. 
El 70\% de las reacciones tífico-paratíficas realizadas con la técnica de aglutinación en placa son positivas sin indicar infección activa, por lo que es importante confirmarlas y cuantificarlas mediante la técnica de dilución en tubo.

\section{COLOFÓN}

Contrariamente a lo dicho en la segunda frase señalada del artículo motivante de estos comentarios, ${ }^{1}$ algunos dicen que: "las variaciones de los títulos de aglutinación, [no] deben utilizarse para 'vigilar la evolución' de un proceso infeccioso. La única manera de hacerlo es la observación clínica". ${ }^{6}$

\section{REFERENCIAS}

1. Rocha MJ. Brucelosis espinal. Acta Médica Grupo Ángeles. 2016; 14 (4): 211-219.

2. Ruiz CM. Valor diagnóstico de las pruebas de laboratorio. En: Brucelosis. México: Ediciones Científicas La Prensa Médica Mexicana, SA; 1986.
3. Poujol ER. Empleo correcto de las reacciones febriles (Welch-Stuart y Widal). Rev Med Hondur. 1996; 64 (1): 31-32.

4. Velázquez BM, Martínez-Barreda C, Ruiz-Reyes G, Ruiz-Argüelles GJ. Inutilidad de las reacciones febriles. LAB-acta. 2000; 12: 47.

5. Ruiz-Argüelles GJ. ¿Por qué los médicos seguimos haciendo cosas innecesarias?: algunas reflexiones con sesgo hematológico. Rev Hematol Mex. 2012; 13 (2): 43-44.

6. Béjar LC. Evaluación de la utilidad de las reacciones febriles de aglutinación: estudio comparativo de resultados entre poblaciones con y sin manifestaciones clínicas de enfermedades infecciosas febriles. [Consultado 06 de enero de 2017] Disponible en: http://www.contactoquimico.com/htm/Articulos/Inmunologia/ Inmunologia6Evaluacion.htm

7. Hamilton HK, Rose MB. Manual de diagnóstico clínico. Editorial Interamericana; 1985; 2. p. 362.

8. Reglas prácticas para interpretar los resultados de las reacciones febriles de aglutinación. Clínica y laboratorio. Boletín de los Laboratorios Clínicos de Puebla. 1995; 13 (9).

Atentamente,

Dr. Guillermo Murillo-Godínez Medicina Interna 